\title{
Research and Application of Air Source Heat Pump Technology at Rd. 60-10 Oil Delivery Site
}

\author{
Shiyao $\mathrm{He}^{1}$, Yuxi $\mathrm{Ji}^{2}$, Wenhong Feng ${ }^{3}$, Liling Wang ${ }^{4}$, Tao Yang ${ }^{5}$, Jintao $\mathrm{Ji}^{6}$, Xuehu Wang ${ }^{7}$, Yang $\mathrm{Li}^{8}$ \\ ${ }^{1}$ Engineering Technology Research Institute of Huabei Oilfield Company, Renqiu, Cangzhou, 062552, China \\ ${ }^{2}$ Department of Technical Supervision and Inspection, Huabei Oilfield Company, Renqiu, Cangzhou, 062552, P.R.China \\ ${ }^{3}$ Department of Technical Supervision and Inspection,Huabei Oilfield Company, Renqiu,Cangzhou,062552,P.R.China \\ ${ }^{4}$ Engineering Technology Research Institute of Huabei Oilfield Company, Renqiu, Cangzhou, 062552, China \\ ${ }^{5}$ No.1 oil production plant of Huabei Oilfield Company, Renqiu, Cangzhou, 062552, China \\ ${ }^{6}$ Plant of Petroleum Machinery, Bohai Equipment Manufacturing Company, China National Petroleum Corporation, Renqiu, Cangzhou, \\ 062552, P.R. China \\ ${ }^{7}$ Erlian branch of Huabei Oilfield Company, Xilin Gol League, Inner Mongolia, 011200, China \\ ${ }^{8}$ Erlian branch of Huabei Oilfield Company, Xilin Gol League, Inner Mongolia, 011200, China
}

\begin{abstract}
The heating methods currently used at oil delivery sites and transfer stations on North China Oilfield include electric bar heating, fuel oil heating, gas heating, etc. The traditional heating methods have adverse effect on energy conservation and environmental protection. They have low energy efficiency of heating and produces great pollution to the environment. The air source heat pump technology uses the heat in the air as the low-temperature heat source and transforms it to the high-temperature hot water, which will later serve as a heat tracing for crude oil gathering and transportation. No combustion effluent is produced in operation and the energy-saving effect is outstanding with high social-benefit.
\end{abstract}

\section{Introduction}

In the process of oil field construction, difficulties in oil pipeline construction might be caused by improper locations of some wells, environmental or some other factors. So it is necessary to install a storage tank in the well site and use an oil tanker to carry out oil and gas. As the crude oil in the storage tank contains bitumen and other viscous substances, it is necessary to heat the storage tank before transportation to improve crude oil fluidity. At present, electric heating rod heating, fuel heating and gas heating are used as the heating methods of oil delivery sites and transfer stations. The traditional heating methods are of low energy efficiency and produce significant pollution to the environment. Facing the increasingly severe environmental problems together with high gas costs, using clean energy to replace conventional energy is the main direction of oil field heating in the future.

\section{Technical principle of ASHP}

Air source heat pump (ASHP) is an energy-saving and environmental-friendly heating technology based on the reversed Carnot cycle. The pump is driven by an electric motor, which uses the steam compression refrigeration cycle as the working principle, and takes ambient air as a cold (hot) source to produce cold (hot) wind or cold (hot) water. The main parts and components include heat exchange equipment, heat source side heat exchange equipment and compressor. ASHP uses the heat in the air as the low-temperature heat source and passes it through the condenser or evaporator in the traditional air conditioner for heat exchange before extracts or releases the heat energy through the circulation system. It uses the unit circulation system to transfer the energy so as to satisfy the users' demand of heating or hot water. Compared with gas, electricity and solar water heater with electric auxiliary heating, ASHP can save $70 \%$ of energy and it has the lowest cost, even lower than solar water heater (with auxiliary electric heating), about $1 / 3$ of the gas water heater, or $1 / 4$ of the electric water heater. So the investment can be recovered in the short term. Each power consumption of $1 \mathrm{KW}$ can generate $4 \mathrm{KW}$ heat energy on average, and the same power consumption is about 3 times more than that of the electric hot water boiler.

The applicable temperature of ASHP is from $-20^{\circ} \mathrm{C}$ to $40^{\circ} \mathrm{C}$. Since the heat energy at the cold end comes from the air, the COP is low, generally around $2 \sim 3$. Restricted by the compressor, it is more applicable to a single well or oil drawing site that is far away from the oil station yard. No combustion effusion is discharged during the operation, causing no damage to the human body and delivering good social benefits.

\section{Case Study}

We conduct an experiment to verify the effectiveness of

aemail: cy3 hsy@petrochina.com.cn, bemail: 61044772@qq.com: 
the ASHP technology by taking Rd. $60-10$ oil delivery site in the third oil production plant as a research pilot. Totally, there are three oil wells (Rd. 60-8x, Rd. 60-9x1, Rd. 6010x) that daily produce 45 tons of liquid and 25 tons of oil, with an average water content of $55.5 \%$. The freezing point of the crude oil is $34^{\circ} \mathrm{C}$, containing $8.7 \%$ wax, 46.10 asphalt gum, with a density of $0.9166\left(20{ }^{\circ} \mathrm{C}\right)$, and it belongs to heavy oil. There are three delivery tanks, with 6 power distribution heating rods of $90 \mathrm{KW}$. Three cars of oil are delivered in two days. To prevent the oil from condensing in the delivery tank and ensure the proper temperature in the tank, we operate the electric heating rod for an average of 10-12 hours per day with an average daily power consumption of $586 \mathrm{KW}$.h.

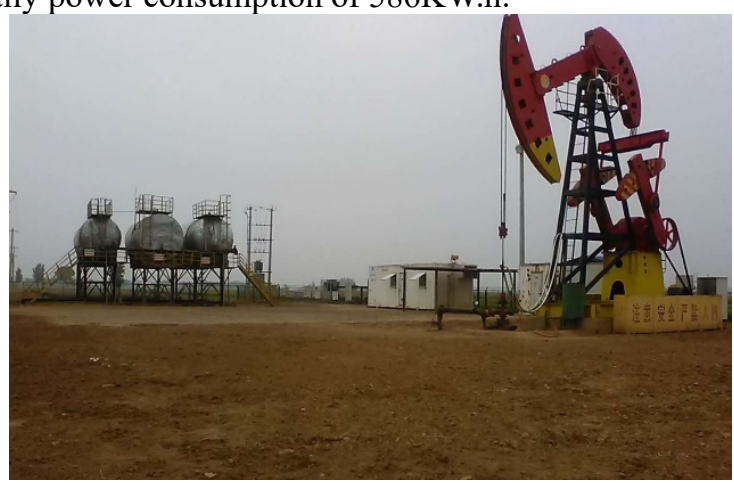

Fig1. Rd. 60-10 Oil Delivery Site

The ASHP is used to replace the original electric heating rod to heat the water, so as to keep the constant temperature of circulating water delivered to the on-site tank and the balance between the inflow and return water flow. The operation mode can be controlled intelligently according to the temperature of the tank. The main parameters of ASHP are as follows:

Rated voltage/phase number/frequency: 380 $\mathrm{V} / 3 \mathrm{~N} \sim / 50 \mathrm{~Hz}$

Waterproof rating: 1PX4

Type of protection against electric shock: Class 1

Rated heating capacity: $96.0 \mathrm{KW}$

Rated cooling capacity: $52.5 \mathrm{KW}$

Rated heating input power: $41.5 \mathrm{KW}$

Rated refrigeration input power: $20.3 \mathrm{KW}$

Rated heating operating current: $75.8 \mathrm{~A}$

Rated cooling operating current: $37.1 \mathrm{~A}$

Maximum input power: $49.8 \mathrm{KW}$

Maximum input current: $91.0 \mathrm{~A}$

Water flow: $16.5 \mathrm{~m} 3 / \mathrm{h}$

Water pressure drop: $56 \mathrm{KPa}$

Inlet/outlet pipe diameter: DN80

Primary refrigerant: R410A

Secondary refrigerant: R134A

Table1. Energy consumption comparison table of air source heat pump and electric heating rod(temperature: $0 \sim 10^{\circ} \mathrm{C}$ )

\begin{tabular}{|c|c|c|c|c|}
\hline $\begin{array}{c}\text { Heating } \\
\text { type }\end{array}$ & $\begin{array}{c}\text { Running } \\
\text { time } \\
(\mathrm{h})\end{array}$ & $\begin{array}{c}\text { Power } \\
\text { consumption } \\
(\mathrm{kw} \cdot \mathrm{h})\end{array}$ & $\begin{array}{c}\text { Power } \\
\text { consumption } \\
\text { per hour } \\
(\mathrm{kw} \cdot \mathrm{h})\end{array}$ & $\begin{array}{c}\text { Average } \\
\text { daily power } \\
\text { consumption } \\
(\mathrm{kw} \cdot \mathrm{h})\end{array}$ \\
\hline $\begin{array}{c}\text { Air source } \\
\text { heat pump }\end{array}$ & 96 & 1534 & 15.98 & 383.50 \\
\hline $\begin{array}{c}\text { Electric } \\
\text { heating rod }\end{array}$ & 96 & 2356.8 & 24.55 & 589.23 \\
\hline
\end{tabular}

From the above table we can see in the environment of $0-10^{\circ} \mathrm{C}$, using ASHP heating can save $205.73 \mathrm{Kw} \cdot \mathrm{h}$ of electricity per day compared to traditional heating methods.

\section{The influence of working fluid on the heat pump's operating features}

The working fluid completes the heat pump cycle in the heat pump system. When the heat pump is working, the working fluid absorbs the heat of the heat source and vaporizes in the evaporator, transferring the heat to the heat sink in the condenser before condensed into liquid. The heat pump system changes with the state of the working fluid to providing heating and cooling. Therefore, different working fluids have a great influence on the operations of the heat pump.

Table2. Parameters of common working fluids

\begin{tabular}{|c|c|c|c|c|}
\hline $\begin{array}{c}\text { workin } \\
\text { g fluid }\end{array}$ & $\begin{array}{c}\text { Condensatio } \\
\mathrm{n} \text { pressure } \\
(\mathrm{kPa})\end{array}$ & $\begin{array}{c}\text { Evaporatio } \\
\mathrm{n} \text { pressure } \\
(\mathrm{kPa})\end{array}$ & $\begin{array}{c}\text { exhaust } \\
\text { temperatur } \\
\mathrm{e} \mathrm{t}\left({ }^{\circ} \mathrm{C}\right)\end{array}$ & $\begin{array}{c}\text { Endothermi } \\
\mathrm{c} \text { ratio v } \\
(\mathrm{m} 3 / \mathrm{Kg})\end{array}$ \\
\hline $\mathrm{R} 22$ & 2174.40 & 354.30 & 90.00 & 0.06708 \\
\hline $\mathrm{R} 123$ & 247.28 & 20.51 & 58.26 & 0.7039 \\
\hline $\mathrm{R} 134 \mathrm{a}$ & 1491.20 & 200.73 & 65.91 & 0.1015 \\
\hline $\mathrm{R} 717$ & 2309.80 & 291.06 & 156.31 & 0.1262 \\
\hline
\end{tabular}

It can be seen from the table that under the same operating conditions, the condensing pressures of R22, R123, R134a, and R717 are different. The order from high to low is $\mathrm{R} 717>\mathrm{R} 22>\mathrm{R} 134 \mathrm{a}>\mathrm{R} 123$. The lower condensing shall be chosen because thin-walled vessels and pipes can be used when the pressure is low. At the same time, the system with lower pressure is safer. If the exhaust temperature of the compressor is too high, it will cause the working fluid and lubricating oil to decompose. It can be seen from the table that the exhaust temperature of the ammonia compressor is much higher than that of the Freon compressor.

\section{Frosting and defrosting of ASHP}

Frosting on the outside heat exchanging machine is an operational problem that cannot be ignored when the pump is working in winter. Frosting reduces the efficiency of the pump and affects the performance of the heat pump units. Defrosting is an energy-consuming process. Therefore, using technical measures to inhibit or delay frosting is very important. There are many ways to inhibit and delay frosting, including to increase the inlet air temperature of the outdoor heat exchanging machine, lower the air humidity, increase the cold surface temperature, upgrade the surface characteristics of the heat exchanger, and realizing a frost-free ASHP. Taking into account the frosting, defrosting and heating of the ASHP in a low-temperature environment, when the outdoor heating temperature is $-20^{\circ} \mathrm{C}$ and the outdoor temperature is lower than $-15^{\circ} \mathrm{C}$, the ASHP unit can operate efficiently during heating period. 


\section{Conclusion}

(1) The ASHP technology can completely replace the traditional heating modes such as electric heating/oil heating/gas heating in oil delivery sites and transfer stations.

(2) As a heavy oil well, Road 60-10 has strict temperature requirements comparing with non-heavy oil ones. In winter, the oil temperature of this well can fully satisfy its production. The ASHP technology can be extended to other non-heavy oil wells.

(3) From the perspective of environmental protection, the promotion of clean energy to replace conventional energy serves as the main direction of future oil field heating.

\section{Reference}

1. Li Lixiang, Zhao Xincai, Fang Zhao, Liang, Changjing, Pan Zhong, et al. Brief analysis of various heating technologies replacing oil fired heating furnace[J]. Petroleum Planning and design,2018(7)

2. Jin Hongwen, Sun Yan, Ma Zhe, Wu Hongwei, Jiang $\mathrm{Na}$,et al. Application of ultra low temperature air source heat pump in severe cold area[J].Journal of Harbin Commercial University,2017(12)

3. Zhao Zengmin, Zhao Sumin, Wu Qiang, et al. Discussion on the application of groundwater source heat pump technology in Tianjin urban area[J]. Engineering Investigation,2006(11)

4. Zhang Jiru, Comprehensive evaluation of water soure heat pump technology in $\mathrm{H}$ energy saving project[J]. Lanzhou Jiaotong University,2017(5)

5. Zhou qi, Zhao Wenxin al. Application of solar energy/heat pump technology in wood drying field[J]. Power demand side management,2017(2) 